\section{AIDS and the heterosexual epidemic}

SIR,-DDr A R Moss (14 February, p 389) stated that "the rapid spread of HIV in drug users appears to be the main source for any future heterosexual epidemic."

On 2 March Professor Michael Adler stated on BBC 2 that studies of the partners of 1000 infected male haemophiliacs showed that the transmission rate to heterosexual partners is low-around $5 \%$. On the same day on ITV, however, Dr Anthony Pinching stated that the chances of contracting the acquired immune deficiency syndrome (AIDS) from an infected person by anal intercourse were $50 \%$ and that the chances of acquiring it by vaginal intercourse were also $50 \%$, which presumably means that if intercourse takes place more than twice the chances are that the infection will be transmitted. This statement is completely in compatible with the two others, and if people were confused before they will be much more confused now.

The somewhat florid ITV programmes were directed particularly at young people, and the response from girls who participated in them shows that the programmes have already induced widespread anxiety about the dangers of ordinary sexual intercourse. A newspaper report of 10 March, quoting the Department of Health and Social Security, stated that the total number of cases of AIDS in Britain was 731, of which only 25 have been among heterosexuals. Of these, only five, of whom four are women, are believed to have acquired the disease through heterosexual intercourse.

There have already been suicides and even murders prompted by a mistaken belief that AIDS has been contracted. How do psychiatrists and sociologists view the prospect of a generation of women who have been conditioned to believe that sexual intercourse is inseparable from the threat of contracting an incurable disease?

To make confusion worse Dr John Seale now argues that the hypothesis that HIV is transmitted primarily by sexual intercourse is badly flawed and offers the alternative suggestion that the virus is a least as likely to be transmitted by infected saliva during kissing. Dr L A Kay (14 March, p 705) suggests an added danger of kissing from various oral and circumoral lesions, all of which he says are very common. Just what $\mathrm{Dr}$ Seale thinks should be done about this is not clear: he condemns the condom campaign as being founded on ignorance, but dispelling ignorance will not in itself halt the spread of the disease. It seems that the only safe course is to limit sexual congress to manua fondling, which suggests a bleak future for the human species

If the medical profession is to achieve any sort of success in the health education campaign against AIDS it desperately needs to get its act together.

JoHN RAWLINS

Standford,

Hampshire GU35 8RH

\section{Propofol infusion for sedation in the intensive care unit}

SIR,-Our own experience with propofol and midazolam in critically ill medical and surgical patients requiring positive pressure ventilation (P G M Wallace et al, European congress on anesthesiology, Vienna 1986; I McA Ledingham et al, unpublished findings) enables us to make a number of observations on the study by $\operatorname{Dr} R M$ Grounds and colleagues (14 February, p 397).

Firstly, it is perhaps hardly surprising that patients receiving intermittent boluses of a drug should have a less easily controllable level of sedation than those receiving a sedative infusion, as in the study by Dr Grounds and coworkers.

The indications for administration of papaveretum remain unclear. The results in the midazolam group seemed unfavourable as patients required significantly more of this drug than those receiving propofol infusion. It was suggested, however, that the nurses may have used papaveretum for its sedative as well as its analgesic properties, presumably including during those periods when sedation "rapidly lightened unexpectedly in some of the patients receiving midazolam." The differences in analgesic requirement must therefore be regarded as speculative.

In spite of these criticisms we agree with Dr Grounds and coworkers that midazolam provides adequate sedation in many patients without complications in intensive care. Slow recovery of consciousness, in our experience, is encountered in sicker and older patients and in those with delayed metabolism. ${ }^{2}$ This feature of treatment with midazolam, generally-though not universally-regarded as undesirable, causes less concern in countries with access to the benzodiazepine blocking agent ro-15-1788 (anexate), an apparently safe and promptly effective drug when swift return of consciousness is considered to be important.

With regard to the propofol infusion rate, $D$ Grounds and colleagues indicated that the low mean requirement of $13.13 \mu \mathrm{g} / \mathrm{kg} / \mathrm{min}$ in their patients was probably attributable to the residual sedative effects of high dose fentanyl during general anaesthesia, and they suggested that highe infusion rates would be required in other circum stances in intensive care. In our studies of critically ill patients, when the range of severity of sickness was larger but the sedation objectives similar, the mean infusion rate was $32 \mu \mathrm{g} / \mathrm{kg} / \mathrm{min}$ (range 17.2 $46.8 \mu \mathrm{g} / \mathrm{kg} / \mathrm{min}$ ). This was associated with significant fall in diastolic and mean arterial pressures as the infusion progressed (though there was no noticeable tissue hypoperfusion). We would therefore recommend caution in the use of propofo infusion in critically ill patients, especially when administered for long periods.

Finally, it should be remembered that all existing studies using prolonged infusions of propofol are covered by clinical trial exemption certificates. Wider use of this or any other new sedative in the critically ill should occur only after careful and detailed assessment under strictly controlled conditions. Extrapolation of the effects of sedative infusions from short to long term administration and from less to more severely ill patients has proved dangerous in the past.

\section{LYNN H NEWMAN}

J C MCDONALD

PG M WALLACE

I MCA LEDINGHAM

Department of Surgery,

Western Infirmary,

Glasgow G11 6NT

1 Newman LH, McDonald JC, Wallace PGM, Ledingham IMcA. Propofol infusion for sedation in intensive care. Anaesthesia (in press).

2 Dundee JW, Collier PS, Carlisle RJT, Harper KW. Prolonged midazolam elimination half life. $\mathrm{Br} \mathcal{f}$ Clin Pharmacol 1986;21:425-9.

SIR,-Dr R M Grounds and colleagues (14 February, $p$ 397) showed that propofol, administered by continuous intravenous infusion, is a highly satisfactory drug for the sedation of patients after cardiac operations. In particular, they showed good control of the level of sedation and quick recovery owing to the lack of cumulation. An unsatisfactory element, however, in the introduction of this drug for general use in intensive care is its price, or economic component, as referred to by J L Appleby (7 February, p 326).

In this four bedded intensive care unit we ventilate about 200 patients a year. The average duration of ventilation is 100 hours for each patient. Diamorphine infusions are used to maintain sedation, at a yearly cost of $£ 3000$ (roughly 5\% of our yearly drug bill). Changing to propofol, assuming a mean infusion rate of $50 \mathrm{mg} / \mathrm{h}$, would cost about $£ 15000$ a year, assuming no tachyphylaxis and no price increases $(200 \mathrm{mg}$ propofol costs £3-4). In view of the fact that this represents a fivefold increase in the cost of sedation there may be a case for rationing this promising drug to those patients in whom rapid awakening is essential.

\section{R F ARMSTRONG} P TAN S MEGPARA

Department of Anaesthesia, University College Hospital, London WCIE 6AU

SIR,-Dr R M Grounds and colleagues (14 February, $p$ 397) failed to note a significantly greater amount of sodium nitroprusside used in the midazolam group $(t=2.893, \mathrm{p}<0.01)$, which implies a greater systemic vascular resistance in that group. Cheng et al, comparing midazolam infusion with placebo as an adjunct to sedation, found a reduction in the requirement of sodium nitroprusside in the midazolam group. ${ }^{1} \mathrm{Dr}$ Grounds and coworkers have described the effect of bolus doses of propofol on systemic vascular resistance, ${ }^{2}$ but they did not determine systemic vascular resistance in this study, merely assuming that the slow infusion had less effect on cardiovascular function.

The emulsifier in propofol, $10 \%$ soya bean oil, is known to accumulate in the lungs of critically ill patients and to "cream" in the serum of patients with high $\mathrm{C}$ reactive protein concentrations.-5 These phenomena will adversely effect gas exchange ${ }^{6}$ and pulmonary vascular resistance, but no objective measure of either variable was described by Dr Grounds and colleagues.

Finally, patients who have undergone cardiac surgery are not representative of admissions to intensive care units in a district general hospital. More common diagnoses for admission are septic shock and the adult respiratory distress syndrome. Drugs used in managing such conditions, with the associated abnormal cardiovascular variables and splanchnic blood flow, will have significantly different pharmacokinetics and pharmacodynamics than when used in the normovolaemic, vasoconstricted patient who has undergone cardiac surgery. Therefore, we conclude that Dr Grounds and others observed no untoward cardiovascular effects only because they did not monitor appropriate haemodynamic and respiratory variables or study a representative group of patients receiving intensive care.

Intensive Care Unit,

G C S BROWN

J D EDWARDS

South Manchester

Manchester M20 7LR

I Cheng EY, Westphal LM, White PF, Sladen RN, Rosenthal MH. Use of midazolam infusion for sedation following aortocoronary bypass surgery. Anesthesiology 1986;65:67

Grounds RM, Morgan M, Lumley J. Some studies on the properties of the intravenous anaesthetic, propofol (Diprivan): a review. Postgrad Med f 1985;61(suppl 3):90-5.

3 Levene MI, Wigglesworth JS, Desai R. Pulmonary fat accumulation after intralipid infusion in the preterm infant. Lancet 1980;ii:815-8.

4 Hessov I, Melson F, Haug A. Postmortem findings in patients treated with intravenous fat emulsions. Arch Surg 1972;114: 66-8. 